\title{
Tratamentos pré-germinativos em sementes de Sesbania virgata cav. pers após o
}

\section{armazenamento}

Pre-germinative treatments in seeds of Sesbania virgata cav. pers after storage

Tratamientos pregerminativos en semillas de Sesbania virgata cav. pers) después o almacenamiento

Recebido: 25/03/2021 | Revisado: 31/03/2021 | Aceito: 09/04/2021 | Publicado: 18/04/2021

Débora Purcina de Moura

ORCID: https://orcid.org/0000-0002-1383-1220 Universidade Federal Rural de Pernambuco, Brasil

E-mail: deborapurcinad@gmail.com

Monalisa Alves Diniz da Silva

ORCID: https://orcid.org/0000-0001-9052-7380 Universidade Federal Rural de Pernambuco

E-mail: monallyysa@yahoo.com.br

Rafael Mateus Alves

ORCID: https://orcid.org/0000-0003-3482-1010 Universidade de São Paulo, Brasil E-mail:rafaelalvesmateus@gmail.com

Robson José Rodrigues Alves

ORCID: https://orcid.org/0000-0001-8210-7212 Universidade Federal Rural de Pernambuco, Brasil E-mail: robsonrodrigues.a19@gmail.com

Elania Freire da Silva

ORCID: https://orcid.org/0000-0002-7176-3609 Universidade Federal Rural de Pernambuco, Brasil E-mail: elania.freire23@gmail.com

Liliane Maria da Silva

ORCID: https://orcid.org/0000-0001-9810-8316 Universidade Federal Rural de Pernambuco, Brasil E-mail: lilianesilva30@hotmail.com

\section{Resumo}

Objetivou-se com o presente trabalho acompanhar o desempenho fisiológico de sementes de Sesbania virgata (Car. Pers) após diferentes condições e períodos de armazenamento, com posterior submissão à tratamentos de superação de dormência. As sementes foram armazenadas em condições não controladas e de geladeira, por períodos de 0; 35 e 70 dias. Foram empregados após cada período de armazenamento cinco tratamentos pré-germinativos de superação de dormência, ou seja, testemunha, imersão em ácido sulfúrico por 15 minutos, imersão em soda cáustica $20 \%$ por 30 e 60 minutos e escarificação com lixa de madeira $\mathrm{n}^{\circ} 100$. Posteriormente, procedeu-se com as seguintes avaliações: teor de água das sementes, porcentagem, índice de velocidade e tempo médio tanto da germinação como da emergência, condutividade elétrica para avaliar a ruptura do tegumento, comprimento e massa seca da parte aérea e do sistema radicular. $\mathrm{O}$ delineamento experimental utilizado foi o inteiramente casualizado, adotando-se um esquema fatorial $2 \times 3 \times 5$ (condições de armazenamento $\times$ períodos de armazenamento $\times$ tratamentos pré germinativos). A escarificação mecânica destacou-se na superação da dormência, a maior liberação de lixiviados foi um indicativo de maior absorção de água, o que resultou no desencadeamento do processo germinativo. O armazenamento em geladeira favoreceu as características referentes à germinação, enquanto o ambiente não controlado resultou nos melhores resultados para os parâmetros de emergência. O armazenamento por 70 dias foi o mais favorável para a conservação da qualidade das sementes de cambaí-amarelo. Desse modo sugere-se para futuros trabalhos a avaliação com períodos de armazenamento mais longos, visando conhecer até que ponto as sementes podem ficar armazenadas sem redução significativa da sua qualidade. Este trabalho mostra ao produtor de mudas que a escarificação com lixa consiste em um procedimento simples e eficaz a ser empregado na superação de dormência, bem como indica uma condição de ambiente satisfatória para a conservação das sementes de $S$. virgata.

Palavras-chave: Cambaí-amarelo; Conservação; Dormência; Vigor.

\begin{abstract}
The objective was to monitor the physiological performance of Sesbania virgata seeds (Cr. Pers) after different conditions and storage periods, with subsequent submission to dormancy overcoming treatments. The seeds were stored in uncontrolled conditions and in refrigerator for period $0 ; 35$ and 70 days. After each storage period, five pregerminative dormancy treatments were used, that is, control, immersion in sulfuric acid for 15 minutes, immersion in $20 \%$ caustic soda for 30 and 60 minutes and scarification with wooden sandpaper $n^{\circ} 100$. Subsequenthy, the following
\end{abstract}


evaluations were carried out: seed water content, percentage, speed index and average germination time of both germination and emergence, electrical conductivity to assess integument rupture, length and dry mass of shoot and root system. The experimental design used was completely randomized, adopting a $2 \times 3 \times 5$ factorial scheme (storage conditions $\mathrm{x}$ storage periods $\mathrm{x}$ pre-germination treatment). Mechanical scarification stood out in overcoming dormancy, the greater release of leachate was an indication of greater water absorption, which resulted in the triggering of the germination process. The storage in refrigerator favored the characteristics related to germination, while the uncontrolled environment resulted in the results for the emergency parameters. The storage for 70 days was the most favorable for conservation of seeds quality of yellow cambaí. In this way, it is suggested for future works the evaluation with longer storage periods, aiming at knowing to what extent the seeds can be stored without significant reduction in their quality. This work shows the seedling producer that sanding scarification is a simple and effective procedure to be used overcome dormancy, as well as indicating a satisfactory environment condition for the conservation of $S$. virgata.

Keywords: Yellow cambaí; Conservation; Dormancy; Vigor.

\section{Resumen}

El objetivo de este estudio fue monitorear el comportamento fisiológico de semillas de Sesbania virgata (Car. Pers) después de diferentes períodos y condiciones de almacenamiento, com posterior sumisión a la latencia superando los tratamientos. Las semillas se almacenaron por períodos de $0 ; 35$ y 70 días, en condiciones incontroladas y frigorífico. Después de cada período de almacenamiento, se se utilizaron cinco tratamientos pregerminativos de latencia, es decir, control, inmersión en ácido sulfúrico durante 15 minutos, inmersión em sosa cáustica al 20\% durante 30 y 60 minutos y escarificación com papel de lija de madeira $n^{\circ} 100$. Posteriormente, se realizaron las seguientes evaluaciones: contenido de agua de las semillas, porcentaje, índice de velocidad y tiempo promedio tanto de germinación como de emergencia, conductividad eléctrica para evaluar la rotura del tegumento, longitud e masa seca de la parte aérea y el sistema radicular. El diseño experimental utilizado fue completamente al azar, adoptando un esquema factorial $2 \times 3 \times 5$ (condiciones de almacenamiento x períodos de almacenamiento x tratamientos pre-germinación). La escarificación mecánica se destacó en la superación de la latencia, la mayor liberación de lixiviados fue un indicio de una mayor absorción de agua, lo que resultó en el desencadenamiento del proceso de germinación. El almacenamiento en el frigorífico favoreció las características relacionadas con la germinación, mientras que el ambiente no controlado resultó en los mejores resultados para los parámetros de emergencia. El almacenamiento durante 70 días fue el más favorable para la conservación de la calidad de las semillas de cambaí amarillo. De esta forma, se sugiere para trabajos futuros la evaluacíon con períodos de almacenamiento más largos, con el objetivo de conocer en qué medida se pueden almacenar las semillas sin una reducción significativa de su calidad. Este trabajo muestra al productor de plántulas que el lijado de la escarificación es un procedimiento simple y eficaz para superar la latencia, además de indicar una consición ambiental satisfaxtoria para la conservación de las semillas de S. virgata.

Palabras clave: Cambaí amarillo; Conservacíon; Latencia; Vigor.

\section{Introdução}

O domínio vegetal Caatinga é formado por uma vegetação composta principalmente de plantas xerófitas, cujas espécies desenvolveram mecanismos de sobrevivência sob condições de baixas pluviometria e umidade relativa do ar (Moraes, 2016). Muitas espécies adaptadas ao semiárido apresentam dispositivos que permitem que seja possível a resistência à seca, apresentando folhas ou folíolos pequenos, com estômatos localizados na parte côncava da folha, espinhos, caules com vasos lenhosos curtos e com diâmetro pequeno e sistema radicular profundo (Araújo Filho, 2013); além de suas sementes apresentarem dormência tegumentar, como uma forma de resistência as condições que são expostas.

Dentre as espécies endêmicas da Caatinga destaca-se a Sesbania virgata (Cav. Pers), arbusto da família Fabaceae (Araújo et al., 2004). Com potencial de uso para revegetação de matas ciliares, reabilitação de áreas degradadas e controle da erosão do solo (Branzini et al., 2012). De acordo com os referidos autores, o gênero Sesbania se sobressai por ser um acumulador de metais pesados, com alta resistência às tensões bióticas e abióticas.

É de vital importância o conhecimento dos processos envolvidos na germinação para preservação e multiplicação das espécies utilizadas nos programas de reflorestamento e recuperação de áreas degradadas (Oliveira; Scheleder; Favero, 2005). Há o consenso geral de que as sementes devem estar devidamente armazenadas, para posterior utilização na formação de mudas ou na semeadura direta. O armazenamento de sementes pode ser definido como um conjunto de técnicas e condições 
para manter a qualidade fisiológica das sementes, de forma a minimizar ao máximo a velocidade do processo de deterioração (Carvalho et al., 2012).

A longevidade das sementes é considerada como uma característica da espécie, desse modo o armazenamento tem grande importância na conservação dos recursos genéticos, sendo que condições inadequadas de armazenamento acabam afetando negativamente a germinação e vigor (Oliveira et al., 2018). No caso de sementes de espécies nativas, diversos são os propósitos do armazenamento, desde a formação de plantios produtivos até a formação de bancos de genes de florestas nativas. É possível também disponibilizar de forma contínua sementes aos programas florestais, contribuindo assim para a recuperação de áreas degradadas e reflorestamento (Floriano, 2004; Barros et al., 2019). Destaca-se assim, a independência do período de disponibilidade natural das sementes, proporcionada pelo armazenamento (Alves et al., 2020). Estes autores verificaram que o armazenamento de sementes de Astronium urundeuva Fr. M. Allemão Engl.) por 180 dias acarretou na diminuição do potencial fisiológico, independente da temperatura e umidade relativa do ar.

As sementes de muitas espécies da Caatinga apresentam dormência tegumentar, o que torna necessário o uso de tratamentos de superação de dormência após o armazenamento, principalmente quando a dormência ainda persiste. Na família das Fabaceae, a causa mais frequente de dormência está associada à impermeabilidade do tegumento, isso ocorre devido à deposição de lignina e ácidos graxos nas camadas das células paliçádicas, baixa densidade de poros nas camadas superficiais e bloqueio do hilo em sementes secas (Coelho et al., 2010).

As sementes de $S$. virgata apresentam dormência tegumentar, desse modo, estudos que forneçam informações sobre a superação da dormência, tornam-se valiosos para as práticas de manejo da espécie, fortalecendo sua utilização em projetos de reposição de cobertura vegetal em áreas degradadas (Silva et al., 2011).

A dormência passa a ser um grande empecilho, quando se considera as atividades de produção de mudas ou mesmo o emprego da semeadura direta, pois faz com que a germinação ocorra de forma desuniforme, atrapalhando principalmente a produção de mudas, além de deixar a semente por um maior período de tempo sujeita a condições adversas, como o ataque de microrganismos, podendo torná-las inviáveis (Silva et al., 2020).

Desse modo o objetivo do trabalho foi avaliar o comportamento de sementes de Sesbania virgata (Car. Pers) durante o armazenamento e o subsequente emprego de tratamentos pré-germinativos para superação da dormência tegumentar.

\section{Metodologia}

Uma pesquisa laboratorial utilizando o método quantitativo foi a metodologia científica adotada na condução desse experimento. Procedeu-se com a coleta de dados numéricos por meio do uso de medições de grandezas que geraram conjuntos de dados, os quais foram analisados por meio de análise estatística (técnica matemática) (Pereira et al., 2018).

O experimento foi conduzido no laboratório de Biotecnologia e Nutrição Vegetal da Universidade Federal Rural de Pernambuco, Unidade Acadêmica de Serra Talhada - PE (UFRPE/UAST). As sementes de Sesbania virgata (Cav. Pers) foram doadas pelo Núcleo de Ecologia e Monitoramento Ambiental (NEMA), Petrolina-PE. As sementes disponibilizadas pelo NEMA foram provenientes do Programa Resgate de Germoplasma do Projeto de Integração do São Francisco-PISF. Após o beneficiamento o lote de sementes foi distribuído em saco plástico, identificado e armazenado em câmara fria com temperatura de 5 a $7^{\circ} \mathrm{C}$ e $20 \%$ de umidade relativa do ar.

\subsection{Armazenamento}

As sementes foram acondicionadas em garrafas plásticas transparentes $(250 \mathrm{~mL})$ e armazenadas por períodos de zero, 35 e 70 dias, nas condições de ambiente não controlado e geladeira. A temperatura e umidade relativa do ar, em cada ambiente, foram monitoradas por um termohigrômetro digital (marca Kasvi), sendo que para as condições de ambiente as médias obtidas 
foram: 35 dias: Temperatura $(\mathrm{T})=35,2^{\circ} \mathrm{C}$ e Umidade relativa do ar $(\mathrm{UR})=40 \% ; 70$ dias: $(\mathrm{T})=32,1^{\circ} \mathrm{C} \mathrm{E}(\mathrm{UR})=45,5 \%$. Para $\mathrm{o}$ armazenamento em ambiente controlado as médias obtidas foram: 35 dias: $(\mathrm{T})=4,4^{\circ} \mathrm{C}$ e $(\mathrm{UR})=53 \% ; 70$ dias: $(\mathrm{T})=7,5^{\circ} \mathrm{C}$ e $(\mathrm{UR})=56 \%$.

\subsection{Tratamentos pré-germinativos}

Após cada período de armazenamento foram empregados cinco tratamentos pré-germinativos de superação de dormência, sendo eles T1- Testemunha, T2- Ácido Sulfúrico por 15 minutos, T3- Soda Cáustica por 30 minutos, T4- Soda cáustica por 60 minutos e T5- Escarificação com lixa de madeira $\mathrm{n}^{\circ} 100$.

Antes (considerando que as sementes já possuem uma qualidade inicial) e após cada período de armazenamento, e subsequente tratamento de superação de dormência, foram determinadas as seguintes características:

\subsection{Teor de água das sementes}

A umidade das sementes foi determinada pelo método de estufa a $105^{\circ} \mathrm{C} \pm 3^{\circ} \mathrm{C}$ por 24 horas, conforme as Regras de Análises de Sementes (Brasil, 2009), observadas na equação abaixo.

$$
T A=\left(\frac{P U-P S}{P U-P L}\right) \times 100
$$

Sendo: TA: Teor de água;

PU: Peso úmido;

PS: Peso seco;

PL: Peso da lata.

Para cada tratamento utilizou duas repetições de 25 sementes.

\subsection{Porcentagem de Germinação}

As sementes foram dispostas sobre duas folhas de papel mata borrão, previamente umedecidas com água destilada com quantidade equivalente a 2,5 vezes o peso do papel seco, acondicionadas em caixas plásticas transparentes conhecidas como gerbox $(11 \times 11 \times 3,5 \mathrm{~cm})$ e mantidas em sala climatizada. Após os períodos zero (momento inicial de amazenamento), 35 e 70 dias de armazenamento, as condições de temperatura e UR ar durante os dias do teste de germinação foram, respectivamente: $25,78^{\circ} \mathrm{C}$ e $49 \%$ durante oito dias; $\mathrm{T}: 25,4^{\circ}$ e $47 \%$ durante 12 dias e $25,95^{\circ} \mathrm{C}$ e $57,33 \%$ durante 10 dias, respectivamente. Ressaltando que, a quantidade de dias que as sementes ficaram na sala de germinação, dependeu da estabilização da germinação, de forma que para cada período de armazenamento a quantidade de dias foi diferente. Considerou-se como critério de germinação a protrusão da raiz primária (2 $\mathrm{mm}$ de comprimento).

\section{5 Índice de velocidade de germinação (IVG)}

Realizado conjuntamente com o teste de germinação, com contagens diárias da protrusão da raiz primária (Maguire,1962).

\subsection{Tempo médio de germinação (TMG)}

Conduzido com o teste de germinação, sendo os resultados expressos em dias (Labouriau, 1983). 


\subsection{Condutividade elétrica (CE)}

Realizada com quatro repetições de 25 sementes, previamente pesadas em balança semianalítica $(0,001 \mathrm{~g})$ e colocadas em recipientes de plástico com $200 \mathrm{~mL}$ de capacidade, contendo $50 \mathrm{~mL}$ de água destilada, por 24 horas. Após o período de embebição, foi procedida leitura da condutividade elétrica da solução de embebição das sementes, sendo os

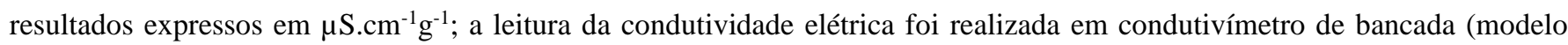
Tec-4MP).

\subsection{Porcentagem de emergência}

Para cada tratamento foram semeadas quatro repetições de 25 sementes em bandejas de plástico de 120 células, tendo como substrato areia umedecida e esterilizada, previamente, por quatro horas à $180^{\circ} \mathrm{C}$. Foi computado após 18 dias o número de plântulas emersas (critério de emergência).

\section{9 Índice de velocidade de emergência (IVE)}

Semelhante ao IVG, considerando-se plântulas normais.

\subsection{Tempo médio de emergência (TME)}

Semelhante ao TMG, considerando-se plântulas normais.

\subsection{Comprimento e massa seca da parte aérea e do sistema radicular}

As plântulas emersas foram retiradas do substrato após a estabilização da emergência (18 dias). Foi avaliada tanto a parte aérea como o sistema radicular, para classificar a plântula como normal ou anormal. Posteriormente mensurou-se o comprimento da parte aérea a partir do colo até o meristema apical, e do sistema radicular do colo até a extremidade da raiz, utilizando uma régua graduada em centímetro, os resultados foram expressos em cm.plântula ${ }^{-1}$.

\subsection{Massa seca da parte aérea e do sistema radicular}

A parte aérea e o sistema radicular, após avaliação do comprimento e retirada dos cotilédones, foram acondicionados em sacos de papel Kraft, previamente identificados e levados à estufa de circulação de ar forçada à $80^{\circ} \mathrm{C}$ por 24 horas. Decorrido este período a massa seca foi pesada em balança analítica com precisão de 0,001g, dividindo-se o valor encontrado pela quantidade de plântulas normais; os resultados foram expressos em plântula-1 (Nakagawa, 1999).

$\mathrm{O}$ delineamento experimental foi inteiramente casualizado com quatro repetições de 25 sementes, adotando-se um esquema fatorial $2 \times 3 \times 5$ (condições de armazenamento, períodos de armazenamento e tratamentos pré-germinativos). Empregou-se o programa estatístico Sisvar e as médias foram comparadas pelo teste Scott-Knott a 5\% (Ferreira, 2014).

\section{Resultados e Discussão}

Os resultados na Tabela 1 mostram que para o teor de água houve interação dupla para os períodos de armazenamento versus os métodos de superação de dormência. Enquanto que a porcentagem e índice de velocidade de germinação apresentaram interação tripla. Essas mesmas variáveis apresentaram interação dupla para períodos de armazenamento versus métodos de superação de dormência, e ainda para condições de armazenamento versus períodos de armazenamento. Evidenciase, portanto que a interação dos fatores interferiu positivamente no processo germinativo. Para o tempo médio de germinação não houve interação significativa para nenhum dos fatores. No caso da condutividade elétrica ocorreu interação significativa 
entre as condições e os períodos de armazenamento. Como também para os períodos de armazenamento e os métodos de superação de dormência.

Tabela 1. Resumo da análise de variância para teor de água (TA), porcentagem de germinação (PG), índice de velocidade de germinação (IVG), tempo médio de germinação (TMG) e condutividade elétrica (CE) de sementes de Sesbania virgata (Cav. Pers), armazenadas em diferentes condições ambientais e períodos, e submetidas posteriormente a tratamentos de superação de dormência, Serra Talhada-PE, 2021.

\begin{tabular}{|c|c|c|c|c|c|c|}
\hline \multirow{2}{*}{ Fontes de variação } & \multicolumn{6}{|c|}{ QM } \\
\hline & GL & TA & PG & IVG & TMG & CE \\
\hline Condições de armazenamento (F1) & 1 & $2,48^{\mathrm{ns}}$ & $202,8^{\text {ns }}$ & $1,00^{\mathrm{ns}}$ & $0,2083^{\mathrm{ns}}$ & $5005,20^{* *}$ \\
\hline Períodos de armazenamento (F2) & 2 & $5,48^{*}$ & $1676,13^{* *}$ & $4,9^{* *}$ & $0,558^{\text {ns }}$ & $2027,60^{*}$ \\
\hline Superação de dormência (F3) & 4 & $41,89^{* *}$ & $21510,53^{* *}$ & $97,15^{* *}$ & $1,943^{\text {ns }}$ & $104777^{* *}$ \\
\hline F1xF2 & 2 & $0,95^{\mathrm{ns}}$ & $554,8^{*}$ & $3,00^{*}$ & $0,208^{\mathrm{ns}}$ & $2793,95^{\mathrm{ns}}$ \\
\hline F1xF3 & 4 & $2,38^{\mathrm{ns}}$ & $419,46^{*}$ & $1,86^{\mathrm{ns}}$ & $0,3012^{\mathrm{ns}}$ & $1166,41^{\mathrm{ns}}$ \\
\hline F2xF3 & 8 & $18,32^{*}$ & $1620,13^{* *}$ & $5,71^{* *}$ & $1,027^{\mathrm{ns}}$ & $1135,61^{*}$ \\
\hline F1xF2xF3 & 8 & $1,21^{\mathrm{ns}}$ & $384,46^{* *}$ & $2,31^{* *}$ & $0,218^{\mathrm{ns}}$ & $859,69^{\mathrm{ns}}$ \\
\hline Erro & 90 & 30 & 90,71 & 0,53 & 1,180 & 488,21 \\
\hline Total & 119 & & & & & \\
\hline $\mathrm{CV}(\%)$ & & 33,79 & 24,78 & 32,25 & 68,12 & 20,17 \\
\hline
\end{tabular}

Teste F: **Significativo a $1 \%$ de probabilidade, *significativo a 5\% de probabilidade; NS: não significativo; CV= coeficiente de variação. Fonte: Autores (2021).

O baixo teor de água em sementes ortodoxas é um dos fatores de maior importância para manter sua viabilidade ao longo do tempo (Fowler, 2000). As sementes por serem higroscópicas podem ganhar ou perder umidade no meio em que estão inseridas (Puzzi, 2000). Dessa maneira é possível observar no período zero de armazenamento (Tabela 2), quando as sementes foram escarificadas manualmente (T5), maior teor de água, diferindo estatisticamente dos demais tratamentos de superação de dormência, o que pode ser explicado pela maior ruptura do tegumento favorecendo as trocas gasosas. Portanto, as sementes que possuem dormência tegumentar quando são submetidas a tratamentos eficientes de superação de dormência, podem trocar mais umidade com o meio que estão inseridas (Albuquerque, 2006). Ainda, observou-se que o teor de água das sementes armazenadas por 35 e 70 dias e posteriormente escarificadas com lixa, declinou em relação ao período inicial. 
Tabela 2. Teor de água de sementes de Sesbania virgata (Cav. Pers), armazenadas em diferentes condições ambientais e períodos, e submetidas posteriormente a tratamentos de superação de dormência. Testemunha (T1), imersão sulfúrico por 15 min. (T2), imersão em soda cáustica por 30 min. (T3), imersão em soda cáustica por 60 min. (T4), escarificação com lixa de madeira ${ }^{\circ} 100$ (T5). Serra Talhada-PE, 2021.

\begin{tabular}{cccc}
\hline & \multicolumn{3}{c}{ Períodos de armazenamento (dias) } \\
\hline $\begin{array}{c}\text { Tratamentos de superação de } \\
\text { dormência }\end{array}$ & $\mathbf{0}$ & $\mathbf{3 5}$ & $\mathbf{7 0}$ \\
\hline T1 & $6,34 \mathrm{Ca}$ & $6,9 \mathrm{Aa}$ & $7,21 \mathrm{Aa}$ \\
T2 & $7,20 \mathrm{Ca}$ & $7,14 \mathrm{Aa}$ & $7,94 \mathrm{Aa}$ \\
T3 & $7,92 \mathrm{Ca}$ & $7,54 \mathrm{Aa}$ & $6,72 \mathrm{Aa}$ \\
T4 & $10,06 \mathrm{Ba}$ & $7,01 \mathrm{Aa}$ & $6,36 \mathrm{Aa}$ \\
T5 & $14,15 \mathrm{Aa}$ & $10,49 \mathrm{Ab}$ & $8,24 \mathrm{Ab}$ \\
\hline
\end{tabular}

Médias seguidas de mesma letra maiúscula na coluna e minúscula na linha, não diferem significativamente entre si, em nível de 5\% de probabilidade. Fonte: Autores (2021).

Na Tabela 3 observou-se que na ausência de armazenamento (zero dia), não houve diferença entre as condições de armazenamento, pois esse período foi utilizado para avaliar a qualidade inicial das sementes. Enquanto que para o período de 35 dias, o armazenamento em geladeira proporcionou porcentagem de germinação significativamente inferior em relação ao ambiente de condições não controladas, tanto para as sementes sem nenhum tratamento como para aquelas imersas em soda cáustica por 60 min. Já no período de 70 dias de armazenamento em condições não controladas, as sementes da testemunha, imersas em ácido sulfúrico por 15 min. e em soda cáustica por 60 min., mostraram-se inferiores em relação as armazenadas em geladeira.

Para todos os períodos e condições de armazenamento a escarificação com lixa (T5) diferiu estatisticamente dos demais tratamentos de superação de dormência, isso ocorreu porque o respectivo tratamento ao romper as camadas impermeáveis do tegumento, permitiu a entrada de água e/ou oxigênio até o endosperma e embrião da semente, com consequente ativação do processo germinativo (Cipriani et al., 2019). 
Tabela 3. Porcentagem de germinação e índice de velocidade de germinação de sementes de Sesbania virgata (Car. Pers), armazenadas em diferentes condições ambientais e períodos, com posterior superação da dormência. Testemunha (T1), imersão em ácido sulfúrico por 15 min. (T2), imersão em soda cáustica por 30 min. (T3), imersão em soda cáustica por 60 min. (T4), escarificação com lixa de madeira ${ }^{\circ} 100$ (T5). Serra Talhada-PE, 2021.

\begin{tabular}{|c|c|c|c|c|}
\hline \multirow{3}{*}{$\begin{array}{c}\text { Condições de } \\
\text { armazenamento }\end{array}$} & \multicolumn{4}{|c|}{ Períodos de armazenamento (dias) } \\
\hline & & 0 & 35 & 70 \\
\hline & \multicolumn{4}{|c|}{ Porcentagem de germinação } \\
\hline \multirow{5}{*}{$\begin{array}{l}\text { Ambiente não } \\
\text { controlado }\end{array}$} & T1 & $4,00 \mathrm{Ca} a$ & $26,00 \mathrm{Ca} a$ & $1,00 \mathrm{Da} b$ \\
\hline & T2 & $5,00 \mathrm{Cb} a$ & $33,00 \mathrm{Ba} b$ & $34,00 \mathrm{Ba} b$ \\
\hline & T3 & $29,00 \mathrm{Bb} a$ & $26,00 \mathrm{Cb} a$ & $44,00 \mathrm{Ba} a$ \\
\hline & T4 & $34,00 \mathrm{Ba} a$ & $41,00 \mathrm{Ba} a$ & $28,00 \mathrm{Ca} b$ \\
\hline & T5 & $100,00 \mathrm{Aa} a$ & $64,00 \mathrm{Ab} a$ & $95,00 \mathrm{Aa} a$ \\
\hline \multirow{5}{*}{ Geladeira } & T1 & $4,00 \mathrm{Ca} a$ & $1,00 \mathrm{Da} b$ & $6,00 \mathrm{Da} a$ \\
\hline & T2 & $5,00 \mathrm{Cb} a$ & $51,00 \mathrm{Ba} a$ & $61,00 \mathrm{Ba} a$ \\
\hline & T3 & $29,00 \mathrm{Bb} a$ & $20,00 \mathrm{Ca} a$ & $33,00 \mathrm{Ca} b$ \\
\hline & T4 & $34,00 \mathrm{Ba} a$ & $25,00 \mathrm{Ca} b$ & $58,00 \mathrm{Ba} a$ \\
\hline & T5 & $100,00 \mathrm{Aa} a$ & $70,00 \mathrm{Ab} a$ & 99,00 Аа $a$ \\
\hline \multirow{2}{*}{$\begin{array}{c}\text { Condições de } \\
\text { armazenamento }\end{array}$} & \multicolumn{4}{|c|}{ Índice de velocidade de germinação } \\
\hline & & & & \\
\hline \multirow{5}{*}{$\begin{array}{l}\text { Ambiente não } \\
\text { controlado }\end{array}$} & T1 & $0,25 \mathrm{Cb} a$ & $1,50 \mathrm{Ca} a$ & $0,00 \mathrm{Cb} b$ \\
\hline & T2 & $0,25 \mathrm{Cb} a$ & $1,50 \mathrm{Ca} b$ & $2,00 \mathrm{Ba} b$ \\
\hline & T3 & $1,75 \mathrm{Ba} a$ & $0,50 \mathrm{Cb} b$ & 2,50Ba $a$ \\
\hline & T4 & $2,00 \mathrm{Ba} a$ & $2,50 \mathrm{Ba} a$ & $1,25 \mathrm{Ba} b$ \\
\hline & T5 & 6,50Aa $a$ & $4,50 \mathrm{Ab} a$ & $5,50 \mathrm{Aa} b$ \\
\hline \multirow{5}{*}{ Geladeira } & T1 & $0,25 \mathrm{Cb} a$ & $0,00 \mathrm{Ca} b$ & $0,25 \mathrm{Ca} a$ \\
\hline & $\mathbf{T} 2$ & $0,25 \mathrm{Cb} a$ & $2,75 \mathrm{Ba} a$ & 3,50Ba $a$ \\
\hline & $\mathbf{T 3}$ & $1,75 \mathrm{Ba} a$ & $0,75 \mathrm{Ca} a$ & $1,25 \mathrm{Ca} b$ \\
\hline & T4 & $2,00 \mathrm{Ba} a$ & $1,25 \mathrm{Cb} b$ & 3,75Ba $a$ \\
\hline & T5 & 6,50Aa $a$ & $4,50 \mathrm{Ab} a$ & $6,50 \mathrm{Aa} a$ \\
\hline
\end{tabular}

Médias seguidas de mesma letra maiúscula e minúscula itálico na coluna e minúscula na linha não diferem entre si, em nível de 5\% de probabilidade pelo teste de Scott-Knott. Letras minúsculas em itálico comparam as condições de armazenamento dentro de cada período. Fonte: Autores (2021).

Segundo Souza et al. (2010) as sementes de S. virgata possuem dormência tegumentar e apresentam baixa taxa de germinação quando intactas, corroborando com os resultados observados no presente trabalho. Estudos com a finalidade de avaliar tratamentos para superação de dormência tegumentar da referida espécie, contribuem com informações práticas aos viveiristas de mudas. Silva et al. (2011) após avaliarem diferentes métodos para superação de dormência de sementes de $S$. virgata, verificaram que a maior porcentagem de germinação (95\%) foi encontrada quando se empregou a escarificação mecânica Resultado semelhante foi encontrado no presente trabalho, onde a utilização da escarificação mecânica com lixa de madeira ${ }^{\circ} 100$ (T5) proporcionou os melhores resultados de porcentagem de germinação ao longo das condições e períodos de armazenamento.

Para o índice de velocidade de germinação (Tabela 3), a escarificação com lixa de madeira nº100 (T5) proporcionou os maiores índices para todas as condições e períodos de armazenamento, esse resultado é em função do tratamento de superação de dormência favorecer a ruptura do tegumento, proporcionando a entrada de água e consequentemente desencadeando o processo germinativo. O índice de velocidade de germinação é considerado um fator decisivo para determinar a qualidade de um lote de sementes, uma vez que quanto maior o seu valor, maior será o vigor do lote (Santos et al., 2018). Freire et al. (2016) verificaram que a escarificação mecânica com lixa foi o tratamento que possibilitou um índice de 
velocidade de germinação estatisticamente significativo em relação aos demais para sementes de Albizia pedicellaris. No período de 35 dias, observou-se que as sementes armazenadas em geladeira germinaram mais rápido do que as armazenadas em condições não controladas, quando após o armazenamento foram imersas em ácido sulfúrico por 15 min. (T2) e soda cáustica por 30 min. (T3). De maneira geral, a maior velocidade de germinação ocorreu quando as sementes foram armazenadas em geladeira por 70 dias, isso porque o maior tempo de armazenamento contribui para o enfraquecimento do tegumento (Marcos-Filho, 2015), favorecendo a absorção de água.

Por ocasião do armazenamento em geladeira por 35 e 70 dias, o segundo tratamento que proporcionou o maior índice de velocidade de germinação foi T2 (imersão em ácido sulfúrico por 10 minutos) e T4 (imersão em soda cáustica por 30 minutos), respectivamente. Kissmanne et al. (2008) encontraram resultados semelhantes para o índice de velocidade de germinação quando sementes de Albizia hasslerii foram armazenadas na condição de ambiente e submetidas a escarificação química com ácido sulfúrico por 20 min.

Para a condutividade elétrica das sementes de $S$. virgata (Tabela 4), o armazenamento em geladeira por 35 dias proporcionou uma maior lixiviação de exsudatos em relação ao armazenamento em condições não controladas, indicando que a baixa temperatura pode ter contribuído para a ruptura do tegumento, favorecendo, portanto uma maior absorção de água. Os demais períodos de armazenamentos não apresentaram diferença significativa para as condições de armazenamento. No ambiente não controlado as maiores lixiviações foram obtidas para os períodos de zero e 70 dias, enquanto que para o armazenamento em geladeira não houve diferença significativa entre os períodos.

Tabela 4. Condutividade elétrica de sementes de Sesbania virgata armazenadas em diferentes períodos e condições ambientais. Serra Talhada-PE, 2021.

\begin{tabular}{cccc}
\hline \multicolumn{4}{c}{ Condutividade elétrica $\left(\boldsymbol{\mu S} \cdot \mathbf{g}^{-1} \cdot \mathbf{c m}^{-1}\right)$} \\
\hline \multirow{2}{*}{ Condições de armazenamento } & \multicolumn{3}{c}{ Períodos de } \\
\cline { 2 - 4 } & $\mathbf{0}$ & $\mathbf{3 5}$ & $\mathbf{7 0}$ \\
\hline \multirow{2}{*}{ Ambiente não controlado } & $107,25 \mathrm{Aa}$ & $87,6 \mathrm{Bb}$ & $114,4 \mathrm{Aa}$ \\
Geladeira & $107,25 \mathrm{Aa}$ & $120,1 \mathrm{Aa}$ & $120,65 \mathrm{Aa}$ \\
\hline
\end{tabular}

Médias seguidas de mesma letra maiúscula na coluna e minúscula na linha, não diferem significativamente entre si, em nível de 5\% de probabilidade pelo teste de Scott-Knott. Fonte: Autores (2021).

O teste de condutividade elétrica é muito eficiente e rápido na determinação da qualidade fisiológica de sementes, baseando-se no principio de quanto maior a quantidade dos lixiviados, maior será a deterioração e consequentemente, menor o vigor das sementes (Avelino et al., 2018). Mas quando as sementes apresentam impermeabilidade do tegumento à agua, não é possível averiguar a qualidade das sementes por meio do teste de condutividade elétrica. Tornando-se necessário o emprego de um procedimento de superação de dormência, sendo que neste caso a entrada de água irá implicar em maior quantidade de lixiviados, o que não significa que a semente seja de qualidade fisiológica inferior, ou seja, que apresente maior deterioração.

$\mathrm{O}$ tratamento que proporcionou os maiores valores de condutividade elétrica (Tabela 5) foi a escarificação com lixa de madeira (T5), em função de possibilitar maior ruptura do tegumento e consequentemente maior liberação de lixiviados; para este mesmo tratamento não houve diferença significativa entre os períodos de armazenamento. A imersão das sementes em soda cáustica por 60 minutos (T4), após o armazenamento por 70 dias, proporcionou uma maior lixiviação em relação aos demais períodos.

Considera-se que o processo de deterioração das membranas das sementes ocorre com o decorrer do tempo, pois segundo Lima et al. (2015), o aumento na quantidade de lixiviados na água de embebição é proporcional ao nível de 
deterioração das sementes. Entretanto ressalta-se que quando as sementes apresentam impermeabilidade do tegumento à água, este preceito deve ser visto com ponderação, haja vista que para que o processo de germinação ocorra, a semente precisa absorver água. Para tanto, há necessidade de um tratamento de superação de dormência, que venha a causar ruptura no tegumento da semente, o que levará a maior lixiviação de exsudatos, sem necessariamente implicar em uma qualidade fisiológica inferior.

Tabela 5. Condutividade elétrica de sementes de Sesbania virgata (Car. Pers) armazenadas por diferentes períodos e posteriormente submetidas à métodos de superação de dormência. Testemunha (T1), imersão sulfúrico por 15 min. (T2), imersão em soda cáustica por 30 min. (T3), imersão em soda cáustica por 60 min. (T4), escarificação com lixa de madeira $\mathrm{n}^{\circ} 100$ (T5). Serra Talhada-PE, 2021.

\begin{tabular}{|c|c|c|c|}
\hline \multirow{3}{*}{$\begin{array}{c}\text { Tratamentos de superação de } \\
\text { dormência }\end{array}$} & \multicolumn{3}{|c|}{ Condutividade elétrica $\left(\mu \mathrm{S} \mathrm{g}^{-1} . \mathrm{cm}^{-1}\right)$} \\
\hline & \multicolumn{3}{|c|}{ Períodos de armazenamento (dias) } \\
\hline & $\mathbf{0}$ & 35 & 70 \\
\hline T1 & $17,25 \mathrm{Ca}$ & $37,12 \mathrm{Ca}$ & $39,12 \mathrm{Ca}$ \\
\hline T2 & $95 \mathrm{Ba}$ & $85 \mathrm{Ba}$ & $103,5 \mathrm{Ba}$ \\
\hline T3 & $100,5 \mathrm{Ba}$ & $92 \mathrm{Ba}$ & $111,75 \mathrm{Ba}$ \\
\hline T4 & $98,5 \mathrm{Bb}$ & $91,37 \mathrm{Bb}$ & $128,5 \mathrm{Ba}$ \\
\hline T5 & $225 \mathrm{Aa}$ & $213,75 \mathrm{Aa}$ & $204,75 \mathrm{Aa}$ \\
\hline
\end{tabular}

Médias seguidas de mesma letra maiúscula na coluna e minúscula na linha, não diferem significativamente entre si, em nível de 5\% de probabilidade pelo teste de Scott-Knott. Fonte: Autores (2021).

\section{Desenvolvimento inicial das plântulas de Sesbania virgata}

Observa-se na Tabela 6 que houve interação tripla apenas para a porcentagem de emergência, essa interação ocorreu entre as condições de armazenamento e os tratamentos de superação de dormência, bem como entre as condições de armazenamento e os períodos de armazenamento. Analisando cada fator isolado, o período de armazenamento apresentou diferença significativa para todas as variáveis, com exceção apenas para comprimento da parte aérea e massa seca do sistema radicular. Enquanto o tratamento de superação de dormência só não apresentou diferença significativa para o comprimento e a massa seca do sistema radicular. As condições de armazenamento foram o único fator isolado que não apresentou diferença significativa para nenhuma das variáveis. 
Tabela 6. Resumo da analise de variância para a porcentagem de emergência (PE), índice de velocidade de emergência (IVE), tempo médio de emergência (TME), comprimento da parte aérea (CPA), comprimento do sistema radicular (CSR), massa seca da parte aérea (MSPA), massa seca do sistema radicular (MSSR) de plântulas de Sesbania virgata (Car. Pers), oriundas de sementes armazenadas em diferentes condições ambientais e períodos, com posterior superação da dormência. Serra TalhadaPE, 2021.

\begin{tabular}{|c|c|c|c|c|c|c|c|c|}
\hline \multirow{2}{*}{ Fontes de Variação } & \multicolumn{8}{|c|}{ QM } \\
\hline & GL & $\mathbf{P E}$ & IVE & TME & CPA & CPR & MSPA & MSSR \\
\hline Condições de armazenamento (F1) & 1 & $5,56^{\mathrm{ns}}$ & $0,03^{\mathrm{ns}}$ & $0,83^{\mathrm{ns}}$ & $2,13^{\mathrm{ns}}$ & $5,63^{\mathrm{ns}}$ & $0^{\mathrm{ns}}$ & $0,0075^{\text {ns }}$ \\
\hline Períodos de armazenamento (F2) & 2 & $1345,63^{*}$ & $28,07^{* *}$ & $7,5^{* *}$ & $132,53^{\mathrm{ns}}$ & $89,42^{* *}$ & $0,62^{* *}$ & $0,0091^{\text {ns }}$ \\
\hline Superação de dormência (F3) & 4 & $6461,13^{*}$ & $41,42^{* *}$ & $8^{* *}$ & $19,97^{* *}$ & $5,42^{\mathrm{ns}}$ & $0,87^{* *}$ & $0,0091^{\mathrm{ns}}$ \\
\hline F1 $\times$ F2 & 2 & $820,43^{* *}$ & $1,60^{\mathrm{ns}}$ & $0,43^{\text {ns }}$ & $9,55^{\mathrm{ns}}$ & $9,5^{\text {ns }}$ & $0^{\text {ns }}$ & $0,0075^{\text {ns }}$ \\
\hline F1 $\times$ F3 & 4 & $477,13^{* *}$ & $1,34^{\mathrm{ns}}$ & $0,04^{\mathrm{ns}}$ & $2,57^{\mathrm{ns}}$ & $0,94^{\mathrm{ns}}$ & $0^{\text {ns }}$ & $0,0075^{\text {ns }}$ \\
\hline$F 2 \times F 3$ & 8 & $574,13^{* *}$ & $5,80^{* *}$ & $0,36^{\mathrm{ns}}$ & $1,95^{\mathrm{ns}}$ & $1,46^{\mathrm{ns}}$ & $0,25^{\mathrm{ns}}$ & $0,0091^{\mathrm{ns}}$ \\
\hline$F 1 \times F 2 \times F 3$ & 8 & $433,18^{\text {ns }}$ & $1,67^{\mathrm{ns}}$ & $0,17^{\mathrm{ns}}$ & $2,40^{\text {ns }}$ & $1,57^{\mathrm{ns}}$ & $0^{\text {ns }}$ & $0,0075^{\text {ns }}$ \\
\hline Erro & 90 & 146,96 & 0,65 & 0,89 & 2,99 & 2,01 & 0,06 & 0,0083 \\
\hline Total & 119 & & & & & & & \\
\hline CV (\%) & & 38,08 & 42,43 & 61,03 & 21,06 & 24,07 & 23,06 & 44,01 \\
\hline
\end{tabular}

Teste F: **Significativo a $1 \%$ de probabilidade, *significativo a 5\% de probabilidade; NS: não significativo; CV= coeficiente de variação. Fonte: Autores (2021).

Para ambas as condições de armazenamento e períodos, o tratamento com escarificação mecânica (T5), proporcionou uma porcentagem de emergência (Tabela 7) estatisticamente superior a todos os demais tratamentos de superação de dormência. Esses resultados ratificam com os encontrados por Santos et al. (2018), ao verificarem que a escarificação mecânica com lixa de madeira proporcionou os maiores valores de porcentagem de emergência para plântulas de $S$. virgata.

Ao longo do armazenamento houve um aumento na porcentagem de emergência (Tabela 7), independente das condições de armazenamento, quando as sementes foram submetidas à escarificação com lixa. Desempenho semelhante foi verificado quando as sementes foram imersas em soda cáustica por 60 min. (T4), após o armazenamento em geladeira. Notouse que para o período de 35 dias, o armazenamento em condições não controladas contribuiu para a melhor formação de plântulas, quando as sementes foram imersas em soda cáustica por 30 e 60 min., não diferindo para os demais tratamentos em relação ao armazenamento em geladeira. Já por ocasião do armazenamento em geladeira por 70 dias, em relação ao ambiente não controlado, a maior formação de plântulas ocorreu a partir das sementes da testemunha e daquelas imersas em ácido sulfúrico (T2) e soda cáustica (T4); já o inverso foi verificado para os demais tratamentos. 
Tabela 7. Porcentagem de emergência de plântulas oriundas de sementes de Sesbania virgata (Car. Pers), armazenadas em diferentes condições ambientais e períodos, com posterior superação da dormência. Testemunha (T1), imersão em ácido sulfúrico por 15 min. (T2), imersão em soda cáustica por 30 min. (T3), imersão em soda cáustica por 60 min. (T4), escarificação com lixa de madeira n ${ }^{\circ} 100$ (T5). Serra Talhada-PE, 2020.

\begin{tabular}{|c|c|c|c|c|}
\hline \multirow{2}{*}{$\begin{array}{c}\text { Condições de } \\
\text { armazenamento }\end{array}$} & \multicolumn{4}{|c|}{ Períodos de armazenamento (dias) } \\
\hline & & 0 & 35 & 70 \\
\hline \multirow{5}{*}{$\begin{array}{c}\text { Ambiente não } \\
\text { controlado }\end{array}$} & T1 & $25 \mathrm{Ba} a$ & $19 \mathrm{Ba} a$ & $12 \mathrm{Ca} b$ \\
\hline & $\mathbf{T 2}$ & $28 \mathrm{Ba} a$ & $26 \mathrm{Ba} a$ & $27 \mathrm{Ba} b$ \\
\hline & T3 & $18 \mathrm{Ba} a$ & $33 \mathrm{Ba} a$ & $39 \mathrm{Ba} a$ \\
\hline & T4 & $28 \mathrm{Ba} a$ & $41 \mathrm{Ba} a$ & $08 \mathrm{Cb} b$ \\
\hline & T5 & 45 Ac $a$ & $64 \mathrm{Ab} a$ & $91 \mathrm{Aa} a$ \\
\hline \multirow{5}{*}{ Geladeira } & T1 & $25 \mathrm{Ba} a$ & $20 \mathrm{Ba} a$ & $35 \mathrm{Ba} a$ \\
\hline & $\mathbf{T 2}$ & $28 \mathrm{Ba} a$ & $25 \mathrm{Ba} a$ & $37 \mathrm{Ba} a$ \\
\hline & T3 & $18 \mathrm{Ba} a$ & $16 \mathrm{Ba} b$ & $26 \mathrm{Ba} b$ \\
\hline & T4 & $28 \mathrm{Bb} a$ & $25 \mathrm{Bb} b$ & $51 \mathrm{Ba} a$ \\
\hline & T5 & $45 \mathrm{Ab} a$ & $55 \mathrm{Ab} a$ & $76 \mathrm{Aa} b$ \\
\hline
\end{tabular}

Médias seguidas de mesma letra maiúscula na coluna e minúscula na linha não diferem entre si, em nível de 5\% de probabilidade pelo teste de Scott-Knott. Letras minúsculas em itálico comparam as condições de armazenamento dos tratamentos dentro de cada período. Fonte: Autores (2021).

Nota-se que todos os tratamentos de superação de dormência (Tabela 8) não diferiram estatisticamente entre si, com exceção apenas da testemunha que apresentou o maior tempo médio de emergência, evidenciando assim a importância de todos esses métodos para superação de dormência de sementes de Sesbania virgata. Por sua vez, segundo Queiroz et al. (2019) a escarificação mecânica com lixa de madeira, embora seja mais trabalhosa, apresentou resultados satisfatórios para a velocidade e o índice de velocidade de emergência de plântulas oriundas de sementes de Mucuna pruriens (mucuna-preta). Para a superação de dormência de sementes de baobá (Adanosonia digitata L.), Araújo et al. (2020) observaram que os tratamentos com ácido sulfúrico e soda cáustica também não diferiram entre si para o tempo médio de emergência, entretanto, diferiram da testemunha.

Tabela 8. Tempo médio de emergência de plântulas de Sesbania virgata oriundas de sementes submetidas a diferentes métodos de superação de dormência. Testemunha (T1), imersão sulfúrico por 15 minutos (T2), imersão em soda cáustica por 30 minutos (T3), imersão em soda cáustica por 60 minutos (T4), escarificação com lixa de madeira $n^{\circ} 100$ (T5). Serra TalhadaPE, 2021.

\begin{tabular}{cc}
\hline Tratamentos de superação de dormência & Tempo médio de emergência (dias) \\
\hline T1 & $2,58 \mathrm{a}$ \\
T2 & $1,29 \mathrm{~b}$ \\
T3 & $1,29 \mathrm{~b}$ \\
T4 & $1,29 \mathrm{~b}$ \\
T5 & $1,29 \mathrm{~b}$ \\
\hline
\end{tabular}

Médias seguidas de mesma letra minúscula na linha, não diferem significativamente entre si, em nível de 5\% de probabilidade pelo teste de Scott-Knott. Fonte: Autores (2021).

Observa-se que para o tempo médio de emergência (Tabela 9), à medida que o período de armazenamento aumentou, as plântulas levaram menos tempo para emergirem. Possivelmente devido ao processo de envelhecimento da semente, já que a dormência tende a ser mais intensa em sementes recém-colhidas, pois ao longo do tempo em que as sementes permanecem na 
natureza ou em condições de armazenamento a dormência é reduzida (Marcos-Filho, 2015); favorecendo, portanto a absorção de água em sementes com dormência tegumentar, e consequentemente o processo de germinação e emergência de plântulas.

Tabela 9. Tempo médio de emergência (TME) e comprimento da parte aérea de plântulas oriundas de sementes, submetidas a diferentes períodos de armazenamento. Serra Talhada-PE, 2021.

\begin{tabular}{ccc}
\hline $\begin{array}{c}\text { Período de } \\
\text { armazenamento }\end{array}$ & $\begin{array}{c}\text { Tempo médio de } \\
\text { emergência (dias) }\end{array}$ & $\begin{array}{c}\text { Comprimento da parte } \\
\text { aérea }(\mathbf{c m})\end{array}$ \\
\hline $\mathbf{0}$ & $2,05 \mathrm{a}$ & $4,5 \mathrm{c}$ \\
$\mathbf{3 5}$ & $1,30 \mathrm{~b}$ & $5,72 \mathrm{~b}$ \\
$\mathbf{7 0}$ & $1,30 \mathrm{~b}$ & $7,57 \mathrm{a}$ \\
\hline
\end{tabular}

Médias seguidas de mesma letra minúscula na linha, não diferem significativamente entre si, em nível de 5\% de probabilidade pelo teste de Scott-Knott. Fonte: Autores (2021)

Ainda na Tabela 9, observa-se que à medida que aumentou o período de armazenamento das sementes, as plântulas de Sesbania virgata apresentaram maior comprimento da parte aérea. Evidenciando que o envelhecimento que ocorre durante o armazenamento contribuiu para superar a dormência tegumentar das sementes, favorecendo o processo de embebição e consequentemente o de emergência e crescimento de plântulas. No entanto, resultados divergentes foram encontrados por Abbade e Takaki (2014), os quais observaram redução acentuada no comprimento de plântulas (parte aérea e sistema radicular) de Tabebuia roseoalba (Ridl.) Sandwith ao longo do armazenamento das sementes, implicando na redução de vigor. Destacase que seja preciso considerar que as sementes de ipê não apresentam dormência tegumentar, diferente das de Sesbania.

A escarificação das sementes com lixa de madeira (T5) após os períodos de zero (sem armazenamento) e 70 dias de armazenamento, possibilitou plântulas com maiores valores de massa seca da parte aérea (Tabela 10). Ursulino et al.(2019) avaliando a massa seca da parte aérea de plântulas de Dimorphandra gardnerianado verificaram que a escarificação mecânica com lixa de madeira $\left(n^{\circ} 120\right)$ também proporcionou os melhores resultados. De um modo geral, à medida que aumentou o tempo de armazenamento diminuiu o acúmulo de massa seca da parte aérea, quando se empregou os métodos de superação de dormência de imersão em soda cáustica por 30 e 60 min. e escarificação com lixa de madeira $n^{\circ} 100$. Dessa forma, estudos futuros com a utilização de mais locais e períodos de armazenamento associados com novos tratamentos de superação de dormência devem ser realizados para essa espécie, buscando entender o seu comportamento no armazenamento e no processo germinativo e no estabelecimento de plantas. 
Tabela 10. Massa seca da parte aérea de plântulas oriundas de sementes de Sesbania virgata (Car. Pers), armazenadas por diferentes períodos, com posterior superação da dormência. Testemunha (T1), imersão em ácido sulfúrico por 15 min. (T2), imersão em soda cáustica por 30 min. (T3), imersão em soda cáustica por 60 min. (T4), escarificação com lixa de madeira $\mathrm{n}^{\circ} 100$ (T5). Serra Talhada-PE, 2021.

\begin{tabular}{cccc}
\hline \multirow{2}{*}{ Tratamentos } & \multicolumn{3}{c}{ Períodos de armazenamento (dias) } \\
\cline { 2 - 4 } T1 & 0 & 35 & 70 \\
\hline T2 & $0,001 \mathrm{Ca}$ & $0,001 \mathrm{Aa}$ & $0,001 \mathrm{Ba}$ \\
T3 & $0,001 \mathrm{Ca}$ & $0,001 \mathrm{Aa}$ & $0,001 \mathrm{Ba}$ \\
T4 & $0,25 \mathrm{Ba}$ & $0,001 \mathrm{Ab}$ & $0,001 \mathrm{Bb}$ \\
$\mathrm{T} 5$ & $0,25 \mathrm{Ba}$ & $0,001 \mathrm{Ab}$ & $0,001 \mathrm{Bb}$ \\
& $0,75 \mathrm{Aa}$ & $0,001 \mathrm{Ab}$ & $0,62 \mathrm{Aa}$ \\
\hline
\end{tabular}

Médias seguidas de mesma letra maiúscula na coluna e minúscula na linha não difere entre si, em nível de 5\% de probabilidade pelo teste de Scott-Knott. Fonte: Autores (2021)

\section{Conclusão}

Escarificação com lixa de madeira mostrou-se o tratamento mais eficiente para superação de dormência de Sesbania virgata (Car. Pers) O armazenamento em geladeira favoreceu as características referentes à germinação, enquanto que o armazenamento em ambiente não controlado possibilitou melhores resultados para os parâmetros de emergência. O período de 70 dias de armazenamento contribuiu para o melhor desenvolvimento das plântulas. Sugere-se para futuros trabalhos a avaliação com períodos de armazenamento mais longos, visando conhecer até que ponto as sementes podem ficar armazenadas sem redução significativa da sua qualidade. Este trabalho mostra ao produtor de mudas que a escarificação com lixa consiste em um procedimento simples e eficaz a ser empregado na superação de dormência, bem como indica uma condição de ambiente satisfatória para a conservação das sementes de $S$. virgata.

\section{Referências}

Abbade, L. C., \& Takaki, M (2014). Teste de tetrazólio para avaliação da qualidade de sementes de Tabebuia roseoalba (Ridl.) Sandwith-Bignoniaceae, submetidas ao armazenamento. Revista Árvore, 38(2), 233-240.

Albuquerque. K. S., Guimarães, R. M; Almeida, I. F., \& Clemente, A. C. S (2006). Métodos para superação de dormência em sementes de Sucupira-Preta (Bowdichia virgiliodes KUNTH). Ciência e Agrotecnologia, 31(6), 1716-1721.

Alves, R. M., Silva, M. A. D., Silva, E. F., Silva, J. N., Moura, D. P., \& Costa, S. A. T (2020). Aspectos germinativos e bioquímicos de diásporos de aroeirado-sertão, armazenados e submetidos ao condicionamento fisiológico. Diversitas Journal, 5(4), 2358-2373.

Araújo filho, J. A (2013). Manejo pastoril sustentável da caatinga. Projeto Dom Helder Câmara.

Araújo. V. A., Silva. D. A. M., Ferraz. F. P. A., \& Brito. V. C. A (2020). Dormência tegumentar de sementes de baobá: Escarificação química. Diversitas Journal, 5 (2). 718-728.

Avelino, S. C. M., Felix, C. F., Silva, G. R. K., Araújo, S. F., \& Pacheco, V.M (2018). Testes bioquímicos de integridade de membranas na avaliação do vigor de sementes de Mimosa caesalpiniifolia Benth. Revista de Ciências Agrárias, 41 (1), 100-108.

Barros, H. S. D., Cruz, E. D., Pereira, A. G., \& Silva, E. A. A (2019). Classificação fisiológica de sementes de maçaranduba quanto a tolerância à dessecação e ao armazenamento. Revista de Ciências Agrárias Amazonian Journal of Agricultural and Environmental Sciences, 62.

Branzini, A., González, S. R., \& Zubillaga, M (2012). Absorption and translocation of copper, zinc and choromium by Sesbania virgata. Journal of Environmental Management,. 102, 50-54.

Carvalho, N. M., Nakagawa, J (2012). Sementes: ciência, tecnologia e produção. (5a ed.), FUNEP. 590. 
Research, Society and Development, v. 10, n. 4, e48810414252, 2021

(CC BY 4.0) | ISSN 2525-3409 | DOI: http://dx.doi.org/10.33448/rsd-v10i4.14252

Cipriani, V. B., Garlet, J., \& Bruna M. L (2019). "Quebra de dormência em sementes de Chloroleucon acacioides e Senna macranthera." Revista de Ciências Agrárias 42(1), 51-60.

Coelho, B. F. M., Maia, S. S. S., Oliveira, K. A., \& Diógenes, P. E. F (2010). Superação de dormência tegumentar em sementes de Caesalpinia ferrea Mart ex Tul. Revista Brasileira de Ciências Agrárias, 5(1), 74-79.

Ferreira, D. F. 2014. Sisvar: A Guide for Its Bootstrap Procedures in Multiple Comparisons. Ciência e Agrotecnologia, 38(2), 109-112.

Freires, M. J., Ataíde, S. H. D., \& Rouws, C. R. J (2016). Superação de dormência de sementes de Albizia pedicellaris (DC.) L. Rico. Floresta e Ambiente, 23 (2), 251-257.

Silva, M. E. P., Santiago, F. E., Doloso, M. P., Silva, M. E., \& Silva, O. J (2011). Quebra de dormência de sementes de Sesbania virgata (Cav.) Pers. Idesia, 29(2). 39-45.

Souza, V. C., Agra. P. F. M., Andrade, L. A., Oliveira, I.G., \& Oliveira, L. S (2010). Germinação de sementes da invasora Sesbania virgata (Cav.) Pers. Sob efeito da luz, temperatura e superação de dormência. Ciências Agrarias, 31(4), 889-893.

Kissmann, C., Scalon, S. P. Q., Mussury. R. M., \& Robania. A. D (2008). Germinação e armazenamento de sementes de Albizia hasslerii (Chod.) Burkart. Revista Brasileira de Sementes, 31(2), 104-115.

Lima, J. J. P., Freitas, M. N., Guimarães, R. M., Vieira, A. R. \& Ávila, M. A. B. (2015). Accelerated aging and electrical conductivity tests in crambe seeds. Ciência e Agrotecnologia, 39(1), 7-14.

Nakagawa, J., Krzyzanowski, F. C., Vieira, R. D., \& França Neto, J.B (1999) Testes de vigor baseados no desempenho das plântulas. Vigor de sementes: Conceitos e Testes, 1-24.

Oliveira, A. K. M., Scheleder, E. J. D., \& Favero, S (2006). Caracterização morfológica, viabilidade e vigor de sementes de Tabebuia aurea (Silva Manso) Benth \& Hook, f. ex. S. Moore. Revista Árvore, 30(1), 25-32.

Puzzi, D (2000). Abastecimento e armazenamento de grãos. Campinas. Instituto Campineiro de Ensino Agrícola, p.666, 2000.

Silva, F. R. B., Lucas, F. M. F., Costa, N. L. T., \& Azevêdo, B.K.T (2020). Tratamentos térmicos para a superação de dormência em sementes de espécies arbórea brasileira. Journal of Biotechnology and Biodiversity, 8(3), 219-224.

Oliveira, M. K. A., Alves, F. F., \& Fernandes, V (2018). Germinação de sementes de Vochysia divergentes após armazenamento em três ambientes. Ciência Florestal, 8(2), 525-531.

Ursulino, M. M., Alvesll, U. E., Araújo, C. P., Alves, M. M., Ribeiro, S. T., \& Silva, S. R (2019). Superação de dormência e vigor em sementes de Fava-d' Anta (Dimorphandra gardneriana Tulasne). Ciência e Floresta, 29(1), 105-115. 